\title{
Isolation and Characterization of Glycosaminoglycans in Human Plasma
}

\author{
I. Staprans and J. M. Felts
}

Veterans Administration Medical Center, San Francisco, California 94121,

and Department of Physiology, University of California, San Francisco, California 94143

\begin{abstract}
We have described methodology for the isolation and quantitation of glycosaminoglycans present in human plasma. Plasma glycosaminoglycans can be quantitatively adsorbed on a DEAESephacel ion exchanger and eluted with a salt gradient as two groups: a low-charge fraction and a high-charge fraction. The low-charge fraction consists of chondroitin sulfate with a low sulfate content and the high-charge fraction consists of heparan sulfate, chondroitin sulfate, and keratan sulfate (type I). We have determined the plasma concentration of each of these glycosaminoglycans in six normal human subjects.

We have established that none of the glycosaminoglycans in plasma are covalently linked to plasma proteins. All are isolated as complexes with plasma proteins in noncovalent linkages. The glycosaminoglycans in the low-charge fraction are bound with high affinity to a single plasma glycoprotein by a lectin-type bond that can be disrupted by a simple glycoside. The highcharge fraction contains three major proteins and several minor proteins associated with the glycosaminoglycans by both lectintype and ionic bonding. The plasma proteins associated with glycosaminoglycans represent $<0.5 \%$ of the total plasma proteins.

Little is known about the physiologic role of the plasma glycosaminoglycans as components of metabolic processes. Because glycosaminoglycans have been implicated in lipid metabolism and atherosclerosis, we tested all of these compounds, isolated in free form, on the in vitro hydrolysis of triglycerides by lipoprotein lipase. Plasma heparan sulfate stimulated the rate of this reaction severalfold. All other plasma glycosaminoglycans were inactive. Thus, plasma heparan sulfate may play an important role in plasma lipoprotein metabolism.
\end{abstract}

\section{Introduction}

Glycosaminoglycans (GAGs) ${ }^{1}$ are widely distributed in human tissues and body fluids and consist of sulfated polymers of hexosamines with uronic acid or hexose. GAG excretion in urine from normal subjects has been extensively studied and urinary GAGs have been well characterized (1-3). The presence of GAGs in human plasma has been demonstrated in several laboratories (4-6); however, these GAGs have not been fully identified and characterized mainly due to their low blood concentration and to a deficiency of adequate methodology.

Address reprint requests to Dr. Staprans, Lipid Research Laboratory (151L), VA Medical Center, 4150 Clement Street, San Francisco, CA 94121.

Received for publication 21 February 1984 and in revised form 20 May 1985.

1. Abbreviations used in this paper: $\mathrm{CS}$, chondroitin sulfate; $\mathrm{C}-4 \mathrm{~S}$, chondroitin 4-sulfate; HS, heparan sulfate; KS, keratan sulfate.

The Journal of Clinical Investigation, Inc.

Volume 76, November 1985, 1984-1991
Calatroni et al. (7) reported that plasma GAGs consist essentially of chondroitin sulfates, which they separated into two different types on the basis of their behavior on ion exchange cellulose. The GAGs that adhered to the cellulose were found to have a high sulfate content and these were classified as "free" GAGs. Those GAGs that did not adhere to the ion-exchange cellulose had a low sulfate content and were classified as "bound" GAGs. These bound GAGs were considered to be covalently linked to one or more plasma proteins. This division of GAGs into free and bound forms was admittedly an operational definition, and the exact nature of the interactions with plasma proteins was not further explored.

Recently, we reported the fractionation of plasma GAGs into low and high charge species by ion-exchange chromatography on DEAE-Sephacel using a gradient elution system (8). In this report we have further identified, characterized, and quantitated the low-charge GAGs and the high-charge GAGs in plasma and have investigated the interaction of these GAG molecules with plasma proteins.

Each of the isolated plasma GAGs was tested in a lipoprotein lipase assay system in order to identify which plasma GAG might influence lipid metabolism.

\section{Methods}

\section{Isolation of GAGs from plasma}

Plasma GAGs were isolated using ion-exchange chromatography. Fresh citrated plasma was obtained from a local blood bank, and $1,000 \mathrm{ml}$ were processed undiluted after addition of $2 \mathrm{mg}$ of gentamycin and 170 mg of phenylmethylsulfonyl fluoride (Sigma Chemical Co., St. Louis, MO). Fresh plasma was used, because cryoprecipitation of plasma causes a major loss of GAG-protein complexes. A DEAE-Sephacel (Pharmacia Fine Chemicals, Piscataway, NJ) chromatography column $(3.0 \times 25.0$ cm) was equilibrated with $0.15 \mathrm{M} \mathrm{NaCl}$ containing $0.02 \mathrm{M}$ Tris $\mathrm{HCl}$, $\mathrm{pH}$ 8.6. Plasma was applied on the column directly at a rate of $50 \mathrm{ml} /$ $\mathrm{h}$ at room temperature. After extensive washing of the column with the equilibrating buffer, the adsorbed material was eluted with a linear salt gradient $(0.15-2.0 \mathrm{M} \mathrm{LiCl}$; total elution volume $300 \mathrm{ml})$ at a rate of 12 $\mathrm{ml} / \mathrm{h}$. The linearity of the salt gradient was established by conductivity measurements. The collected fractions $(10 \mathrm{ml}$ each) were tested for protein and uronic acid in order to determine the elution profile for the GAGs; however, the values for uronic acid under these experimental conditions are not quantitative due to the interference of color development by glycoproteins associated with the GAGs. The pattern showed two clear peaks, dividing the plasma GAGs into low-charge (peak I) and highcharge (peak II) species. Uronic acid-containing fractions for each peak were pooled and dialyzed in dialysis tubing (Spectrapor, Spectrum Medical, Los Angeles, CA; 2,000 molecular weight cutoff) against distilled water. The fractions were then lyophilized.

To test for complete adsorption of low-charge plasma GAGs by the DEAE-Sephacel column, the charge and wash effluent were analyzed further. A portion $(100 \mathrm{ml})$ was freed of protein as follows: $1 \mathrm{ml}$ of cysteine $(0.5 \mathrm{M})$ and $1 \mathrm{ml}$ of EDTA $(0.5 \mathrm{M})$ were added to the aliquot and the $\mathrm{pH}$ was adjusted to 6.2 with $2.5 \mathrm{M}$ acetic acid. Digestion was carried out with $4.0 \mathrm{mg}$ papain (Type IX, Sigma Chemical Co.) for 48 $h$ at $56^{\circ} \mathrm{C}(7)$. The digest was clarified by centrifugation at $8000 \mathrm{~g}$ and 
the residue washed. The wash was combined with the original digest and placed on a small DEAE-Sephacel column $(0.5 \times 2.0 \mathrm{~cm})$. The column was eluted with a salt gradient as described below for the purification of low-charge plasma GAGs and the fractions tested for uronic acid-containing material. For comparison, $100 \mathrm{ml}$ of the original plasma was digested as described above and total low-charge GAGs contained in that volume were isolated and quantitated. This permitted a calculation of the percent recovery of the low charge GAGs.

\section{Purification of plasma GAGs}

Low-charge plasma GAGs (peak I). We have found that low-charge GAGs are associated with a plasma glycoprotein. The association can be disrupted by sodium dodecyl sulfate (SDS), $\alpha$-methyl-D-mannoside $(0.5$ $\mathrm{M})$, or by digestion with $\alpha$-mannosidase. The complex is not disrupted by $2 \mathrm{M} \mathrm{NaCl}, 8 \mathrm{M}$ urea, or $6 \mathrm{M}$ guanidine hydrochloride. To obtain the protein-free GAGs from peak I the following method was used. The lyophilized peak I fraction containing $\sim 2.5 \mu \mathrm{mol}$ uronic acid was dissolved in $1.0 \mathrm{ml}$ of $0.05 \mathrm{M}$ citrate buffer, $\mathrm{pH} 4.5$, and was digested with $0.02 \mathrm{U}(0.08 \mathrm{mg})$ of $\alpha$-mannosidase (Miles Laboratories, Inc., Elkhart, IN) for $18 \mathrm{~h}$ at $37^{\circ} \mathrm{C}(9)$. The mannosidase was essentially free of protease activity under these conditions. The digest was then applied on a DEAESephacel column $(0.5 \times 2.0 \mathrm{~cm})$, which had been equilibrated with 0.15 $\mathrm{M} \mathrm{NaCl}, 0.02 \mathrm{M}$ Tris $\mathrm{HCl}, \mathrm{pH}$ 8.6. The column was eluted with a salt gradient $(0.15-1.0 \mathrm{M} \mathrm{LiCl}, 0.02 \mathrm{M}$ Tris $\mathrm{HCl}, \mathrm{pH} 8.6$; total elution volume of $40 \mathrm{ml}$ ). Fractions of $0.8 \mathrm{ml}$ were collected, dialyzed, and tested for protein and uronic acid. The uronic acid-containing fraction was free of protein as determined by the method of Lowry et al. (see Reference 23). This fraction was dialyzed, lyophilized, and used for further analysis.

High-charge plasma GAGs (peak II). We have found that the highcharge GAGs are associated with several plasma proteins and this association can be disrupted by SDS, $\alpha$-methyl-D-mannoside $(0.5 \mathrm{M})$ or by digestion with $\alpha$-mannosidase followed by treatment with trichloroacetic acid (TCA) or $8 \mathrm{M}$ urea. To obtain the protein-free GAGs from peak II the following method was used. The lyophilized peak II fraction containing $\sim 2.5 \mu \mathrm{mol}$ uronic acid was digested with $\alpha$-mannosidase and chromatographed as described for peak I. Chromatography showed that this treatment does not dissociate all of the proteins, however, the uronic acid-containing fractions could be completely free of protein by precipitation of the digested fraction with TCA $\left(5 \%, 0^{\circ} \mathrm{C}\right)$. The protein-free supernate containing several GAGs was dialyzed and lyophilized and used for further analysis.

\section{Enzymatic digestion of plasma GAGs}

To identify GAGs contained in peak I and peak II, aliquots of $1.0 \mathrm{ml}$ of the protein-free GAG fractions, each containing $\sim 1.0 \mu \mathrm{mol}$ uronic acid, were digested at $37^{\circ} \mathrm{C}$ for $18 \mathrm{~h}$ with one or more of the following eliminases: chondroitinase ABC or AC (Sigma Chemical Co.), $1.0 \mathrm{U} / \mathrm{ml}$ in $0.1 \mathrm{M}$ sodium acetate, $\mathrm{pH} 8.0$ (10); keratanase (Miles), $0.05 \mathrm{U} / \mathrm{ml}$ in $0.05 \mathrm{M}$ Tris- $\mathrm{HCl}, \mathrm{pH} 7.4$ (11); heparitinase (Miles Laboratories, Inc.), $0.5 \mathrm{U} / \mathrm{ml}$ in $0.05 \mathrm{M}$ acetate, $\mathrm{pH} 7.0$ (12). The specificity and efficiency of all enzymes were confirmed on GAG standards by digesting them under similar conditions. The enzymatic digests of GAG standards and of isolated plasma GAG fractions were dialyzed, lyophilized, and analyzed by electrophoresis together with untreated GAG standards.

\section{Agarose gel electrophoresis}

Electrophoresis of GAGs was performed as described by Horner (13). An LKB Multiphor apparatus (LKB Instruments, Gaithersburg, MD) and commercial electrophoresis plates (Corning universal electrophoresis film) containing $1.0 \%$ agarose were used. Electropheresis was carried out in $0.06 \mathrm{M}$ barbital buffer at $\mathrm{pH} 8.6$ and discontinued when the amaranth tracking dye had traveled a distance of $4.5 \mathrm{~cm}$. The plates were stained for $10 \mathrm{~min}$ with toluidine blue $(0.1 \%$ in water) and destained in running tap water. The following GAG samples were used as standards: beef lung heparan sulfate (HS), whale cartilage chondroitin 4-sulfate (C-4S), and bovine corneal keratan sulfate (KS). HS and C-4S were a gift from Dr. A. Cifonelli of the University of Chicago. KS was purchased from Miles Laboratories, Inc.

\section{Isolation of plasma high-charge $H S, C S$, and $K S$}

Each species of GAG was obtained separately by digestion of the other two plasma high-charge GAGs. Aliquots of the protein-free high-charge GAG fraction (peak II) containing $2.0 \mu \mathrm{mol}$ uronic acid were dissolved in $1.0 \mathrm{ml}$ of sodium acetate buffer, $0.1 \mathrm{M}, \mathrm{pH} 7.0$ containing specific eliminases and were digested at $37^{\circ} \mathrm{C}$ for $18 \mathrm{~h}$. The remaining intact GAG was reisolated from the digestion mixture by rechromatography on a small DEAE-Sephacel column. Each individual plasma GAG was collected between salt concentrations of 0.35 and $1.0 \mathrm{M} \mathrm{LiCl}$, and the fraction was dialyzed to remove salt and any remaining digestion fragments. The GAG solution was then lyophilized.

\section{Measurement of lipoprotein lipase activation by GAGs}

Assay of lipoprotein lipase activity was carried out as previously described (3). $1-\mathrm{ml}$ reaction mixtures consisted of: $0.1 \mathrm{ml}$ of $1.3 \mathrm{M}$ Tris- $\mathrm{HCl}, \mathrm{pH}$ $8.6 ; 0.1 \mathrm{ml}$ of $0.02 \mathrm{M} \mathrm{CaCl}_{2} ; 0.3 \mathrm{ml}$ of $15 \%(\mathrm{wt} / \mathrm{vol})$ crystalline bovine serum albumin (Sigma Chemical Co.); $0.1 \mathrm{ml}$ of $10 \%$ Intralipid (Vitrum, Stockholm, Sweden); $0.015 \mathrm{ml}$ of apolipoprotein C-II, $0.2 \mathrm{mg} / \mathrm{ml} ; 0.10$ $\mathrm{ml}$ of purified milk enzyme; and $0.30 \mathrm{ml}$ was allowed for other additions in water, such as GAG. Apolipoprotein C-II concentration was chosen for half-maximal activation of the enzyme in this reaction mixture. The volume was made up with distilled water. Duplicate samples were incubated for $60 \mathrm{~min}$ at $37^{\circ} \mathrm{C}$. Free fatty acids were extracted (14) and their content was determined by titration with tetrabutylammonium hydroxide (15). Reaction mixtures lacking the apolipoprotein C-II were incubated under the same conditions to serve as control blanks. GAG activation was defined as the activity in addition to that obtained with apolipoprotein C-II alone and is expressed in units as micromoles of free fatty acids released per hour per milliliter of reaction mixture. The release of free fatty acids was linear for $60 \mathrm{~min}$ in this assay system.

\section{Gel filtration chromatography}

The approximate molecular weights of free and protein-associated plasma GAGs were estimated by gel filtration chromatography on a Sephacryl S-300 (Pharmacia Fine Chemicals) column $(1.3 \times 90 \mathrm{~cm})$ equilibrated with $0.5 \mathrm{M} \mathrm{NaCl}$. The column was calibrated with reference GAGs of known approximate molecular weights as follows: heparin $(9,000)$, heparin $(14,000), \mathrm{C}-4 \mathrm{~S}(15,000), \mathrm{KS}(25,000), \mathrm{C}-6 \mathrm{~S}(29,000)$, HS $(34,000)$ and hyaluronic acid $(230,000)$. No standards were available for the low molecular weight range. The elution pattern was established by ultraviolet absorption and/or uronic acid determination and lipoprotein lipase activation on each fraction. When the elution volume (in milliliters) was plotted against the log of molecular weights, a straight line was obtained. From this plot, the approximate molecular weight range was determined for low-charge and high-charge plasma GAGs and for the protein associated GAG complexes. The reference GAG compounds were a gift from Dr. A. Cifonelli of the University of Chicago.

\section{Quantitation of plasma GAGs}

Freshly drawn plasma $(100 \mathrm{ml})$ from six normal fasted subjects was diluted to $0.10 \mathrm{M} \mathrm{NaCl}$ concentration and chromatographed on a DEAESephacel column as described above for GAG isolation. However, the salt gradient was started at $0.1 \mathrm{M} \mathrm{LiCl}$ to insure total recovery of all lowcharge GAGs. Fractions in peak I (low-charge GAGs) and in peak II (high-charge GAGs) were pooled and the protein was removed by papain digestion (7) and the GAGs reisolated using small DEAE-Sephacel columns. The total low-charge GAG (CS) in peak I material was determined using the carbazole method for uronic acid determination. In the highcharge GAG fraction, KS was measured by the anthrone reaction using corneal $\mathrm{KS}$ as a standard. Because HS content in human plasma is very low (16), colorimetric methods could not be used. This GAG was determined in the high-charge GAG mixture by activation measurements of the lipoprotein lipase enzyme reaction. A standard activation curve was derived from purified plasma HS and, thus, the HS concentration in the unknown was determined from such an activation curve. The concentration of the high charge CS in plasma was derived after the value of HS was subtracted from the total value of HS plus CS obtained by uronic acid determination on the high-charge GAG fraction. 


\section{Analytical methods}

Uronic acid was determined by the method of Bitter and Muir (17) using glucuronolactone as a standard. Hexosamine was determined as described by Boas (18) and sulfate was determined with sodium rhodizonate (19). Galactose in KS was measured by the anthrone reaction (20). Nitrous acid degradation was performed according to the method of Cifonelli (21) and alkali treatment was performed in $0.5 \mathrm{~N} \mathrm{NaOH}$ at $5^{\circ} \mathrm{C}$ for 24 h (22). Protein content was determined by using the method of Lowry et al. (23) with bovine serum albumin as a standard. Proteins were examined by SDS-polyacrylamide slab gel electrophoresis according to the method of Laemmli (24) and glycoproteins were stained with Shiff's reagent (25). Identification of amino sugars was carried out by thin layer chromatography using a modification of the method of Martz and Krivis (26). Glucosamine, galactosamine (Sigma Chemical Co.), C-4S, KS, and HS (Miles Laboratories, Inc.) were used as reference compounds.

\section{Results}

Isolation of GAGs from human plasma. The GAG-protein complexes in plasma adhere to DEAE-Sephacel by virtue of the highly negatively charged sulfate groups on the GAG molecules. Under the conditions used most plasma proteins do not adhere to DEAE-Sephacel. Fig. 1 shows an elution pattern of uronic acid-containing peaks which results when the GAG-protein complexes are eluted with a salt gradient. Using this technique we have separated plasma GAGs into a low-charge (peak I) and a high-charge (peak II) species. These results are in agreement with our earlier observations that plasma contains a large lowcharge GAG fraction and a smaller high-charge GAG fraction (8).

We have determined that quantitative adsorption of all plasma GAGs to a DEAE-Sephacel column is dependent on the ionic strength of the plasma sample applied. To estimate any low-charge GAGs that were not adsorbed on the DEAE-Sephacel column by direct application of plasma, we analyzed the initial eluate and the wash. An aliquot was digested with papain and the GAGs were reisolated and analyzed as described in Methods. When the amount of GAG contained in the wash was compared to the amount contained in the same aliquot of whole plasma, we found that only $80 \%$ of low-charge GAGs adsorbed at a salt concentration of $0.15 \mathrm{M}$. However, if the plasma was diluted to $0.10 \mathrm{M}$ salt, all of the GAGs were adsorbed and none appeared in the wash. These results establish that all GAG species can be adsorbed on a DEAE-Sephacel ion exchanger under appropriate experimental conditions together with those plasma proteins that form complexes with the GAGs.

Because all adsorbed plasma GAGs were isolated in association with plasma proteins, an attempt was made to isolate protein-free GAGs from both peak I and peak II without proteolytic digestion. Fig. 2 shows the elution pattern resulting when peak I (Fig. 1) material was chromatographed on a small DEAESephacel column before (Fig. $2 A$ ) and after (Fig. $2 B$ ) digestion of this fraction with $\alpha$-mannosidase. This enzyme removes terminal mannose from glycoproteins and dissociates the protein and the GAG. Elution of the GAG with a salt gradient produced a single uronic acid-containing peak essentially free of protein. Similar results were obtained when peak I material was not digested with $\alpha$-mannosidase, but was chromatographed on a DEAE-Sephacel column in a buffer containing either $0.5 \mathrm{M} \alpha$ methyl-D-mannoside or $0.1 \%$ SDS.

Fig. 3 shows the elution pattern of the high-charge GAG fraction (peak II, Fig. 1) chromatographed on a DEAE-Sephacel column with a shallow salt gradient (Fig. $3 \mathrm{~A}$ ). If we digested the high-charge GAG fraction with $\alpha$-mannosidase, $\sim 50 \%$ of the protein was dissociated and could be completely removed from the GAGs by rechromatography of the digested fraction on a DEAE-Sephacel column (Fig. 3 B). This dissociation is

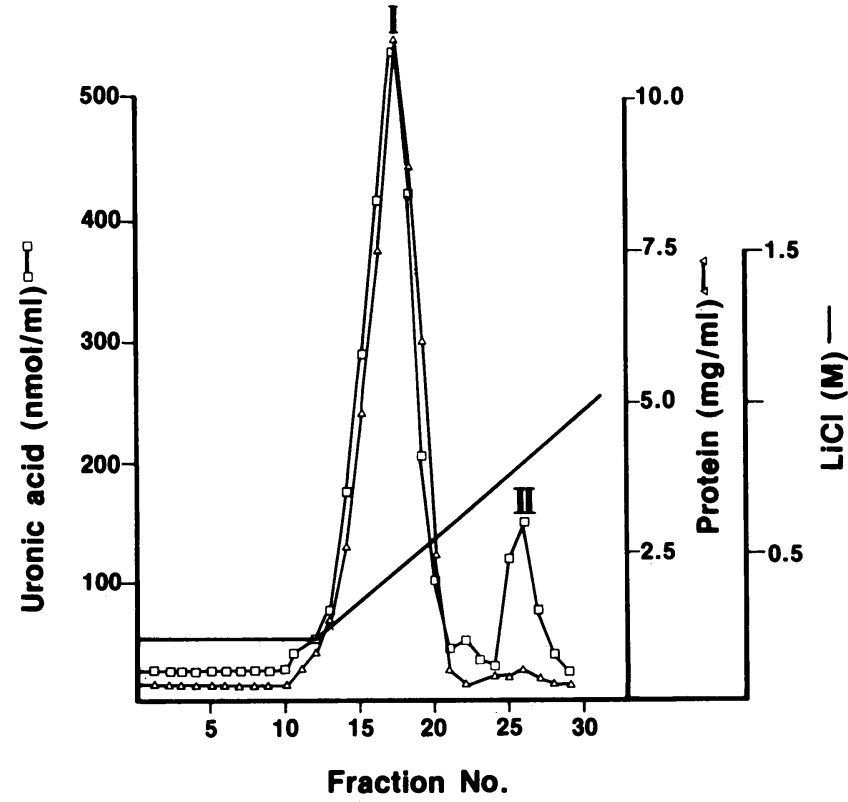

Figure 1. Elution pattern of plasma GAG-protein complexes. Fresh plasma $(1,000 \mathrm{ml})$ was directly applied on a DEAE-Sephacel column in $0.15 \mathrm{M}$ salt. Most plasma proteins did not adhere to the column at this salt concentration. The adsorbed material was eluted with a linear salt gradient. Peaks I and II represent the low-charge and high-charge plasma GAG fractions, respectively.

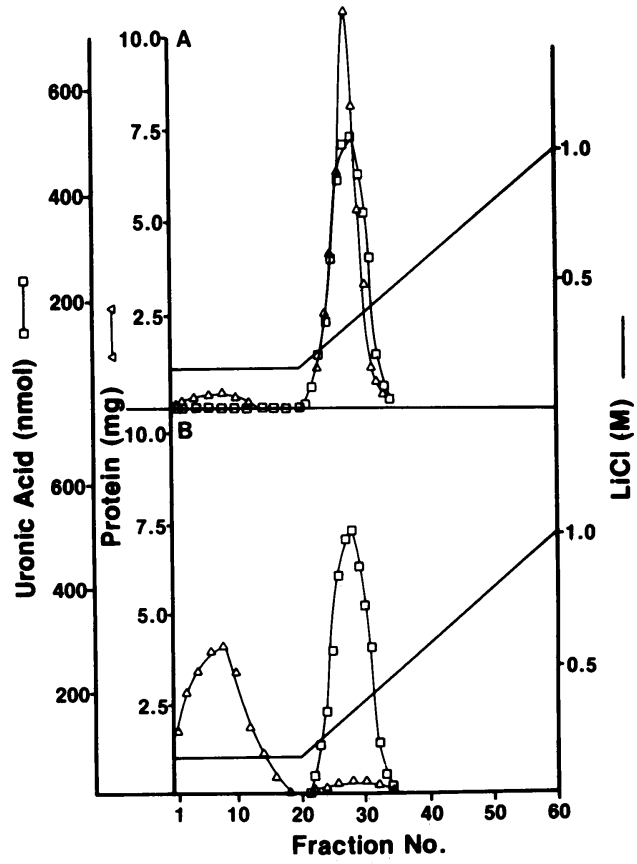

Figure 2. Elution patterns of the low-charge GAG fraction (peak I, Fig. 1) from a DEAE-Sephacel column. $(A)$ Pattern of untreated plasma low-charge GAG fraction. (B) Pattern of plasma low-charge GAG fraction treated with $\alpha$-mannosidase. 


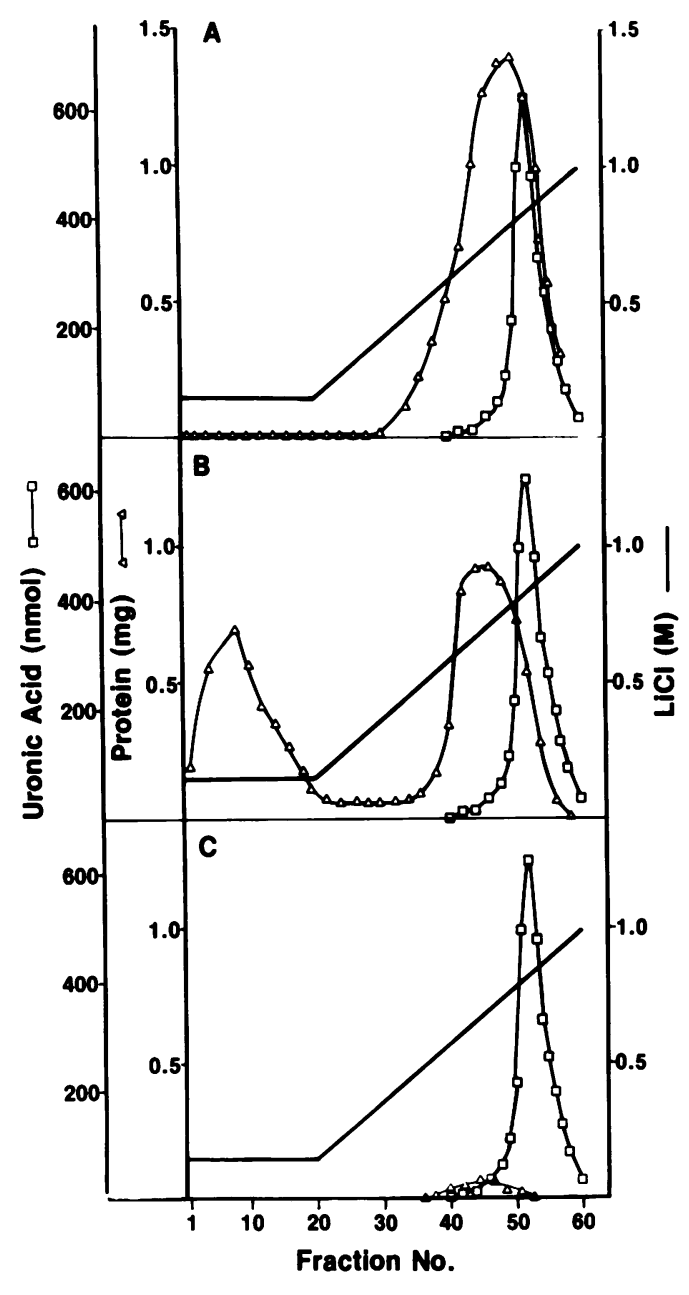

Figure 3. Elution patterns of the plasma high-charge GAG fraction (peak II, Fig. 1) from a DEAE-Sephacel column. ( $A$ ) Pattern of the untreated high-charge GAG fraction. $(B)$ Pattern of the high-charge GAG fraction treated with $\alpha$-mannosidase. $(C)$ Pattern of the TCA supernatant from the $\alpha$-mannosidase-treated high-charge GAG fraction.

probably due to the hydrolysis of the terminal mannose of the glycoproteins which then no longer can form a GAG-glycoprotein complex. These glycoproteins can also be removed if the ion-exchange chromatography of the high-charge GAG fraction is performed in a buffer containing $0.5 \mathrm{M} \alpha$-D-methyl-mannoside or $0.1 \%$ SDS which apparently disrupts the GAG-glycoprotein interaction. The glycoproteins that are removed by disrupting the mannose-mediated bond and appear in the wash fractions (Fig. $3 B$ ) do not precipitate with TCA, but will co-precipitate if the precipitation with TCA is carried out on the intact peak II material.

After $\alpha$-mannosidase treatment, the remaining proteins associated with the high-charge GAG fraction then can be removed by precipitation with $\mathrm{TCA}\left(5 \%, 0^{\circ} \mathrm{C}\right)$ or by rechromatography in the presence of $8 \mathrm{M}$ urea. This suggests that this protein(s) is associated with the GAGs by ionic interaction. Fig. $3 C$ shows that when the TCA supernatant from the mannosidase-treated high-charge GAG fraction is rechromatographed, only a negligible quantity of protein remains and the GAGs can be isolated protein free. The elution pattern of the uronic acid-containing material was not altered by the deproteinization procedures. It should be noted that TCA precipitation or chromatography in
$8 \mathrm{M}$ urea can be successfully carried out only after the removal of the glycoproteins. If the TCA precipitation is performed on the intact high-charge GAG fraction (Fig. 1; peak II), the majority of the high-charge GAGs will co-precipitate with the protein.

Characterization of protein-free GAGs by agarose electrophoresis. The electrophoretic patterns of all protein-free plasma GAGs are shown in Fig. 4. The GAGs were freed of protein as described above. The low-charge GAG from peak I (Fig. 1) gave a single band (channel $A$ ). This material was susceptible to digestion by chondroitinase $\mathrm{ABC}$ or $\mathrm{AC}$ (see Methods) and no stainable material remained. In agarose electrophoresis the relative mobility of this plasma GAG is 0.63 which is slower than that of reference cartilage $\mathrm{C}-4 \mathrm{~S}(0.79$, channel $F)$. The slower mobility of the low-charge CS can be explained by a lower sulfate content of this material compared to our reference compound (Table I). These results show that peak I GAG is undersulfated CS. It is the most abundant GAG in plasma in confirmation of earlier reports $(7,27,28)$.

The high-charge GAGs from peak II (Fig. 1) were examined by agarose electrophoresis. Channel $B$ shows several bands obtained from this fraction. When this material was digested with chondroitinase $\mathrm{ABC}$ or $\mathrm{AC}$, a part of the faster-moving band was removed (channel $C$ ). These results indicate the presence of CS in the high-charge GAG fraction. The mobility of this GAG is similar to the mobility of reference C-4S (channel $F$ ). The chondroitinase ABC-resistant high-charge GAG (channel $C$ ) was digested with other specific eliminases. The slower moving band was susceptible to digestion by keratanase (channel $D$ ) and displayed mobility similar to that of reference corneal KS, type I (channel $G$ ). This evidence demonstrates that plasma contains KS of type I. The remaining band (channel $D$ ) had a mobility similar to that of reference bovine lung HS (channel $E$ ). It was susceptible to degradation by both nitrous acid and heparitinase

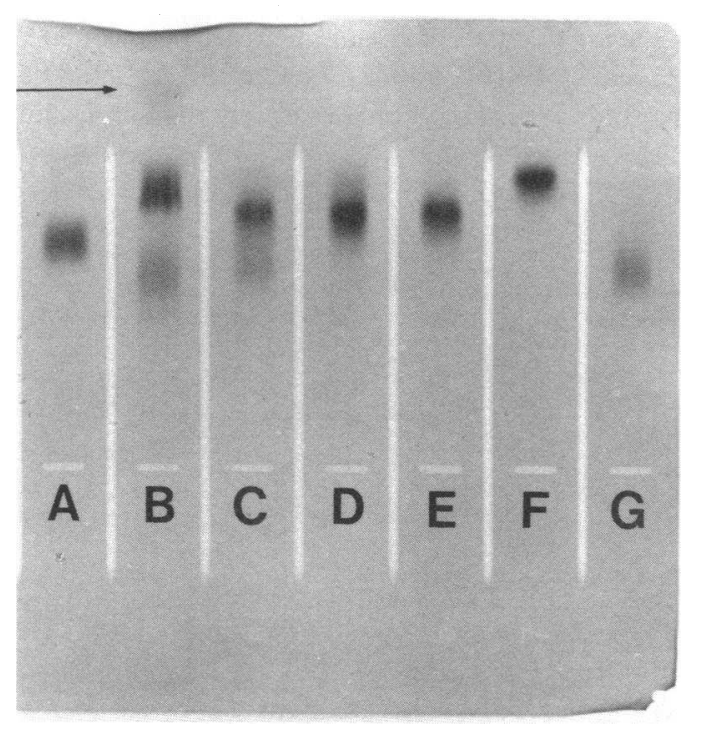

Figure 4. Agarose gel electrophoresis pattern of plasma protein-free GAGs and reference standards. $(A)$ Plasma low-charge CS; $(B)$ plasma high-charge GAGs; $(C)$ plasma high-charge GAGs after treatment with chondroitinase $\mathrm{ABC} ;(D)$ plasma high-charge GAGs after treatment with chondroitinase $\mathrm{ABC}$ and keratanase; $(E)$ reference $\mathrm{HS} ;(F)$ reference C-4S; $(G)$ reference $\mathrm{KS}$ (type I). The arrow indicates amaranth tracking dye. Channels without stainable material (i.e., digested GAGs from $A$ and $D$ ) are not shown. 
Table I. Partial Characterization of Purified Plasma GAGs and Reference GAGs

\begin{tabular}{|c|c|c|c|c|}
\hline Glycosaminoglycans & Hexosamine identification & $\begin{array}{l}\text { Sulfate to } \\
\text { hexosamine ratio }\end{array}$ & $\begin{array}{l}\text { Relative mobility by } \\
\text { agarose electrophoresis* }\end{array}$ & $\begin{array}{l}\text { Approximate molecular } \\
\text { weight range }\end{array}$ \\
\hline Heparan sulfate (plasma) & Glucosamine & 1.22 & 0.71 & $<5,000 ; 70,000$ \\
\hline Heparan sulfateł (beef lung) & Glucosamine & 0.97 & 0.71 & 32,000 \\
\hline $\begin{array}{l}\text { Chondroitin sulfate (plasma low- } \\
\text { charge) }\end{array}$ & Galactosamine & 0.43 & 0.63 & $<5,000$ \\
\hline $\begin{array}{l}\text { Chondroitin sulfate (plasma high- } \\
\text { charge) }\end{array}$ & Galactosamine & 0.94 & 0.79 & $<5,000 ; 70,000$ \\
\hline Chondroitin 4-sulfateł (whale cartilage) & Galactosamine & 0.98 & 0.79 & 15,000 \\
\hline Keratan sulfate (plasma) & Glucosamine & 1.31 & 0.55 & $<5,000 ; 70,000$ \\
\hline Keratan sulfate§ (corneal) & Glucosamine & 1.37 & 0.55 & 25,000 \\
\hline
\end{tabular}

* Mobility of GAGs/mobility of tracking dye. $¥$ Reference compounds obtained from Dr. A. Cifonelli: molecular weights were obtained by sedimentation. § Reference compound obtained from Miles Laboratories, Inc.

and no stainable material remained. This evidence demonstrates that plasma high charge GAG (peak II) contains HS, which is in agreement with our preliminary observation (8). Channels without stainable material are not shown in the figure.

Gel filtration of plasma high-and low-charge GAG-protein complexes and isolated protein-free GAGs. The protein-GAG complexes (peak I and peak II, Fig. 1), isolated from human plasma, were chromatographed in $0.5 \mathrm{M} \mathrm{NaCl}$ on a Sephacryl S-300 gel filtration column calibrated with GAG standards. Thus, the molecular weights for these complexes are only approximate (Fig. 5). The chromatography yielded two uronic acid-containing peaks that corresponded to approximate molecular weights of 20,000 for the low-charge fraction (peak I) and $>100,000$ for the high-charge fraction (peak II), in that it eluted in the column void volume. In an examination of the protein portion in each GAG complex by SDS gel electrophoresis (Fig. 6), peak I gave a single band corresponding to a molecular weight of 19,000. Peak II gave three major bands with molecular weights of 77,000, 55,000 , and 22,000 as well as several minor bands. It should be noted that this study was carried out on freshly drawn plasma

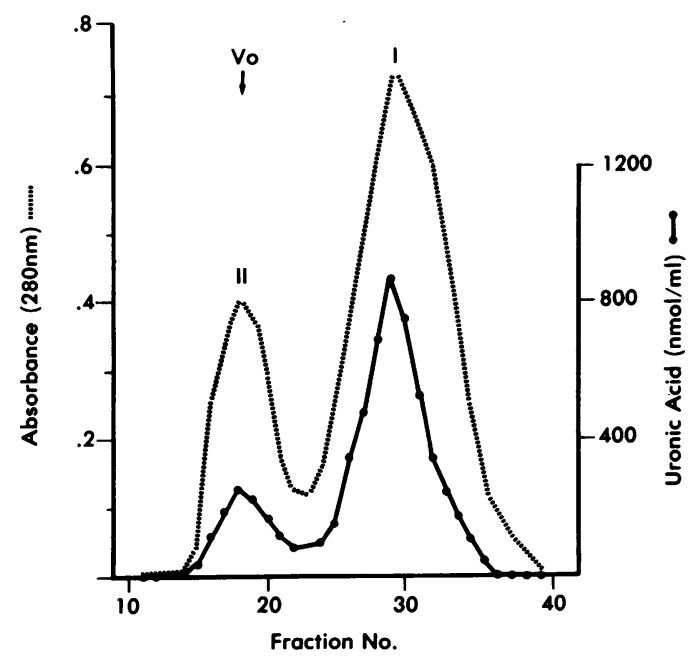

Figure 5. Sephacryl S-300 gel filtration pattern of protein-GAG complexes in $0.5 \mathrm{M} \mathrm{NaCl}$ (3.8 ml per fraction). The high-charge GAG fraction (peak II, Fig. 1) elutes at the void volume (II). The low-charge GAG fraction (peak I, Fig. 1) elutes with a maximum at 20,000 (I). containing a protease inhibitor. The total protein associated with low-charge GAG is $\sim 30 \mathrm{mg} / \mathrm{dl}$ of plasma. The total protein associated with the high charge GAGs is $\sim 1 \mathrm{mg} / \mathrm{dl}$. These proteins constitute $<0.5 \%$ of the total plasma proteins. The peptide in peak I and the two high molecular weight peptides in peak II gave a positive Shiff reaction indicating the presence of carbohydrate.

Fig. 7 shows the elution profile when the protein-free GAGs were examined by gel filtration on Sephacryl S-300 in $0.5 \mathrm{M}$ $\mathrm{NaCl}$. Low-charge plasma $\mathrm{CS}$ eluted as a single peak with an approximate molecular weight of 5,000 or less. This is in agreement with results described by Nakashima et al. (29). However, for the high-charge GAGs there was no agreement with previously published findings (27). We found that when plasma highcharge GAGs were examined by gel filtration, all three GAGs (HS, KS, CS) appeared polydisperse with a wide range of molecular weights. The high-charge GAGs eluted in two groups displaying maxima of 70,000 and 5,000 or less. Each of the fractions from gel filtration was examined for activation of the lipoprotein lipase reaction. This determination demonstrated the same polydispersity. Results with the anthrone reaction (not shown) agreed with the uronic acid determinations. Thus, it

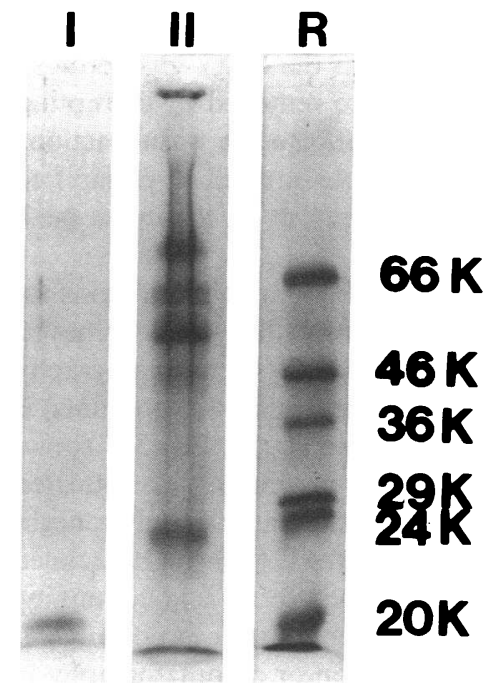

Figure 6. SDS-polyacrylamide gel patterns of the protein portion of the GAG-protein complexes. The low-charge GAG-protein complex yields one band $(I)$ corresponding to a molecular weight of 19,000 and can be stained with both protein and carbohydrate stain. The high-charge GAG-protein complex (II) yields three major bands corresponding to molecular weights of 77,000, 55,000, and 22,000 . The 77,000 and 55,000 bands can be stained with both protein and carbohydrate stains. The reference proteins are shown $(R)$. 


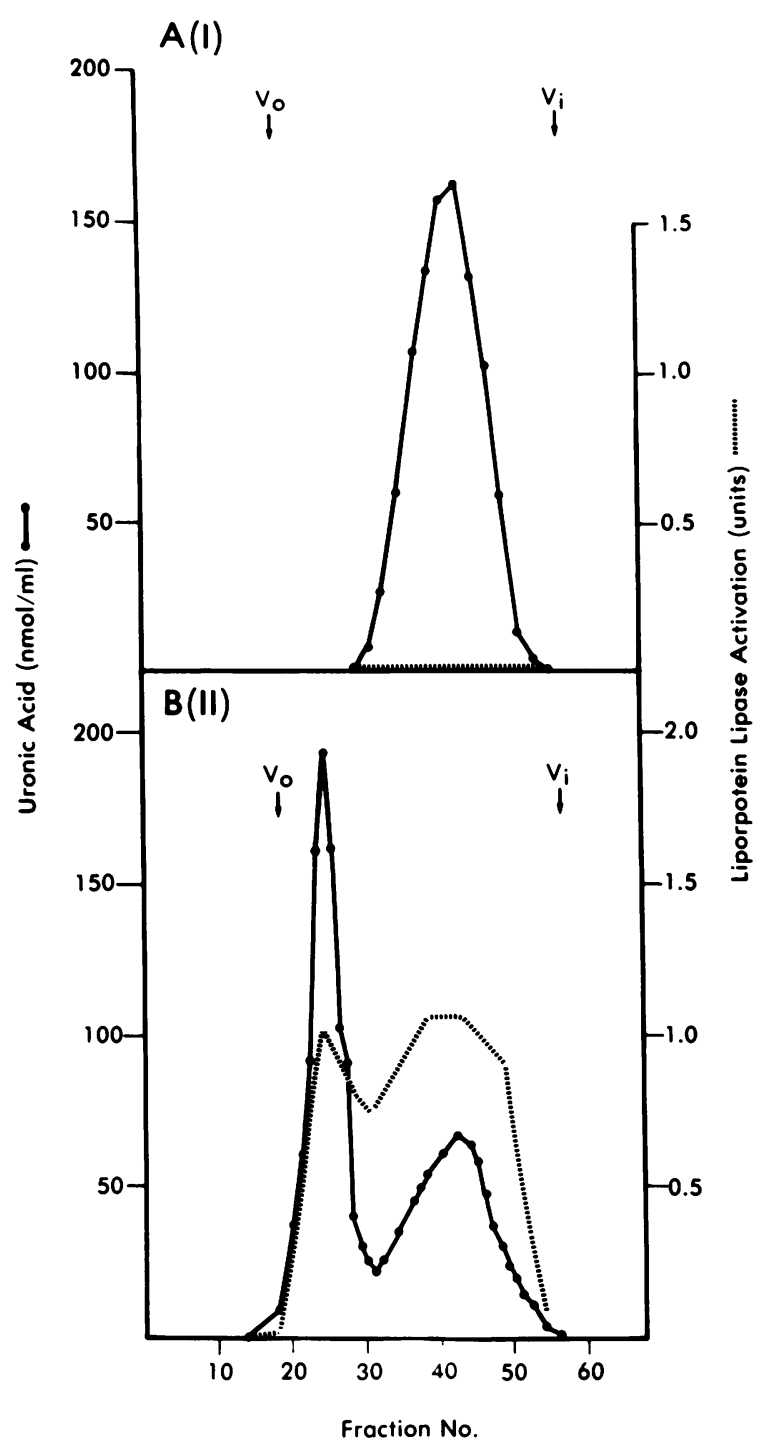

Figure 7. Sephacryl S-300 gel filtration patterns of protein-free GAGs in $0.5 \mathrm{M} \mathrm{NaCl}$ (3.4 ml per fraction). The low-charge GAG (peak I, Fig. 1) elutes with a maximum at $<5,000(A)$. The high-charge GAGs (peak II, Fig. 1) elute as two groups with maxima at 70,000 and $<5,000(B)$. Both species contain all high-charge GAGs. The elution of HS is indicated by lipoprotein lipase activity.

appears that all three high-charge GAGs are present in both weight ranges. The size of the small plasma GAGs is similar to the urinary GAGs (HS and CS) described by us previously (3). It should be noted that the polydispersity of plasma GAGs was not eliminated by alkali degradation or by additional digestion with papain or protease $\mathbf{K}$. No protein was detected in any of these fractions by UV absorbance or by the method of Lowry et al. (23).

Partial characterization of protein-free plasma GAGs. Table I shows the summary of the results obtained when each purified plasma GAG was examined for sulfate content, relative mobility in agarose electrophoresis, the identity of hexosamine, and the approximate molecular weights.

Activation of lipoprotein lipase by isolated plasma GAGs. Each of the isolated GAGs from plasma was tested in the lipoprotein lipase assay in the presence of apolipoprotein C-II (Fig. 8 ). There was no activation when the protein-free CS from the

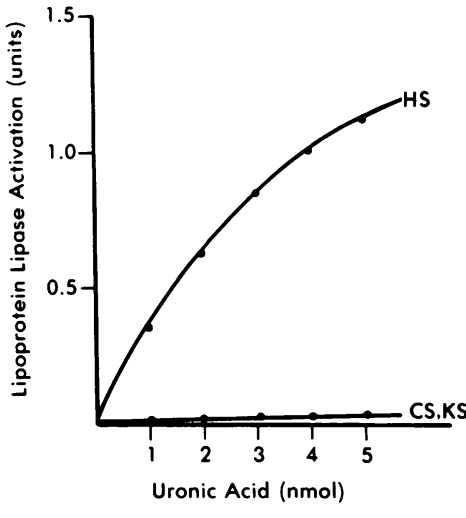

low-charge fraction (peak I, Fig. 1) was added to the assay mixture. Isolated high charge CS and KS gave no activation, however, isolated HS stimulated the lipoprotein lipase reaction severalfold. This activation could be abolished by nitrous acid degradation or by digestion with heparitinase.

Quantitation of plasma GAGs. Table II shows that the most abundant GAG found in human plasma is low-charge CS. However, our values for low-charge CS are higher than the values published by Calatroni et al. (7). The discrepancy is undoubtedly due to the conditions used by these authors for the isolation of GAGs and due to the glycoprotein interference in uronic acid measurements. Our results show that the high-charge GAGs constitute $\sim \mathbf{4 0 \%}$ of the total GAGs. HS constitutes a small fraction of the high-charge GAGs. This finding is in agreement with our previous measurements for plasma $\mathrm{HS}$ by a modified affinity electrophoresis method (16).

\section{Discussion}

In this article, we describe methodology for the isolation, identification, and quantitation of GAGs present in human plasma. Plasma GAGs can be quantitatively adsorbed by DEAE-Sephacel at a salt concentration of $0.10 \mathrm{M}$ and can be eluted with a salt gradient. Plasma GAGs elute as protein complexes in two groups: a low-charge fraction and a high-charge fraction. We have identified the GAGs in both fractions and have shown that, contrary to previous reports $(7,30)$, none of the GAGs in plasma are covalently linked to plasma proteins. Our results suggest that GAGs are transported in plasma in association with selected plasma proteins and glycoproteins by lectin-type and ionic-type bonding.

Table II. GAG Concentration in Human Plasma

\begin{tabular}{lllll}
\hline Subject & HS & CS & KS & $\begin{array}{l}\text { Low charge } \\
\text { CS }\end{array}$ \\
\hline & $n m o l ~ U A^{*} / d l$ & $n m o l ~ U A^{*} / d l$ & $n m o l ~ H A^{*} / d l$ & $\mu m o l ~ U A^{*} / d l$ \\
1 & 62 & 1,006 & 375 & 4.06 \\
2 & 55 & 962 & 693 & 3.98 \\
3 & 20 & 1,112 & 255 & 2.75 \\
4 & 43 & 1,151 & 269 & 3.13 \\
5 & 43 & 1,090 & 394 & 3.35 \\
6 & 38 & 1,004 & 391 & 3.34 \\
Average \pm SD & $44 \pm 14.5$ & $1,054 \pm 73.9$ & $396 \pm 157.9$ & $3.44 \pm 0.503$ \\
& & & & \\
\hline
\end{tabular}

\footnotetext{
* UA, uronic acid; HA, hexosamine.
} 
The most abundant GAG in plasma is a single species of undersulfated CS which we describe as the low-charge fraction. It elutes from a DEAE-Sephacel column at a low salt concentration $(0.20 \mathrm{M})$ as a complex in association with a single protein. This peptide contains carbohydrate and has a molecular weight of 19,000 as determined by SDS polyacrylamide gel electrophoresis. We will further identify this plasma glycoprotein in future studies. The protein-CS complex can be dissociated by $\alpha$-Dmethyl mannoside and the GAG separated from the glycoprotein by ion exchange or gel filtration chromatography. The complex can also be disrupted by digestion of this fraction with $\alpha$-mannosidase. Because the protein-GAG complex is stable in $2.0 \mathrm{M}$ $\mathrm{NaCl}, 6 \mathrm{M}$ guanidine hydrochloride and $8 \mathrm{M}$ urea, it can be concluded that the binding of the low-charge CS to the carbohydrate moiety of the glycoprotein is a biospecific lectin-type bond and cannot be considered as a simple charge-related phenomena. Because the nature of this bond, up to now, has been assumed to be covalent, the only previous method used for obtaining the protein-free, low-charge GAG has been by proteolytic digestion.

Plasma GAGs in the high-charge GAG fraction elute from DEAE-Sephacel at a high salt concentration $(0.8 \mathrm{M})$ and contain three high-charge GAGs in association with several plasma proteins. This GAG mixture contains both lectin-type and ionictype bonding with the associated proteins. Components of the complex can be partially dissociated by $\alpha$-D-methyl mannoside or by digestion with $\alpha$-mannosidase. Thus, it can be concluded that mannose is an important component in the GAG-protein complex formation and the bonding may be lectin in nature. However, the remaining components of the protein-GAG complex require disruption of ionic bonds for the complete removal of protein. Thus, the high-charge GAG complex consists of both lectin-type and ionic bonds that have to be disrupted in a specific sequence if the associated GAGs are to be quantitatively recovered free of protein. The three major proteins present in this fraction have molecular weights of 77,000,55,000, and 22,000. The peptides with molecular weights of 77,000 and 55,000 contain carbohydrate. These will be further identified in future studies.

The protein-free GAGs in the high-charge fraction were identified as CS, HS, and KS (type I). No heparin was found in this fraction. The identification was made on the basis of electrophoretic mobility in $1 \%$ agarose gel, susceptibility to digestion by specific eliminases, susceptibility to chemical degradation with nitrous acid, sulfate/hexosamine ratios, and the nature of the amino hexoses. To our knowledge, this is the first instance where plasma HS and KS have been isolated and clearly identified. Calatroni et al. (7) found that their plasma "free" GAG fraction contained material that was hyaluronidase resistant and gave positive tests for gluscosamine and galactose. This led them to speculate that small amounts of HS and KS could be present. However, their findings were based on a crude high-charge fraction that was not free of glycoproteins.

In contrast to plasma, in which the high-charge GAGs are found as high molecular weight complexes with proteins, urinary high-charge CS and HS are found protein free (3). Urinary highcharge CS and HS are closely related to the CS and HS found in plasma on the basis of electrophoretic mobility and analytical data (3). Thus, it would appear that urinary GAGs are derived from plasma GAGs. KS, which exists in plasma, is not found in urine (3). Purified plasma high-charge GAGs exhibit a marked polydispersity by gel filtration, but a large portion of plasma CS and HS appear in a low molecular weight range $(<5,000)$. Urinary GAGs (CS and HS) are only found in this molecular weight range $(<5,000)(3)$. Thus, it seems that in plasma the higher molecular weight CS and HS are depolymerized to smaller units which are then filtered and appear in urine. Alternatively, the high and low molecule weight species may represent two separate metabolic pools of the high-charge GAGs. There is no information concerning the mechanism whereby the small proteinfree GAGs in urine are derived from the high molecular weight GAG-protein complexes in plasma. Also, the mechanism of filtration of these highly negatively charged molecules is not accounted for by current filtration theory (31). The relatively large quantities of the high-charge GAGs excreted in urine per $24 \mathrm{~h}$ (3), compared to their low plasma concentration reported here, suggest a high turnover of these plasma GAGs.

The most abundant plasma GAG, low-charge $\mathrm{CS}$, is not found in normal human urine; however, this material is present in large quantities in the urine from nephrotic patients where the permeability of the glomerular capillaries has been altered (3). In nephrotic urine, low-charge GAG is found as a complex with a glycoprotein that appears to be identical to that in the plasma low-charge GAG fraction on the basis of its dissociation characteristics (3) and molecular weight.

The biological role of the individual plasma GAGs is not known. Previously we have shown that urinary HS stimulates lipoprotein lipase in vitro and have suggested that in plasma this GAG may play a role in nephrotic hyperlipemia (3). In order to examine if any of the plasma GAGs might influence plasma lipoprotein metabolism, we studied the effects of each plasma GAG in an in vitro lipoprotein lipase enzyme reaction. Because lipoprotein lipase is the enzyme system primarily responsible for the initial clearance of plasma chylomicrons and very low density lipoproteins, any influence on the rate of this enzyme reaction could lead to a change in plasma lipid levels. We found that HS is the only plasma GAG that stimulates the lipoprotein lipase reaction in the presence of apolipoprotein CII. These results are consistent with our preliminary findings (8).

In conclusion, we have identified and quantitated four plasma GAGs and have presented evidence that these GAGs are found in plasma not covalently bound to proteins. All GAGs appear to be transported in plasma associated with plasma proteins by lectin-type and/or ionic bonding. Because plasma HS can affect the rate of the lipoprotein lipase reaction, this compound may be important in modulating the metabolism of lipoproteins. The function of the other sulfated GAGs has not been defined.

\section{Acknowledgments}

The expert assistance of Ms. Agnes Frank, Mr. Robert Butts, and Mr. Lee Bruno is gratefully acknowledged. We thank Mr. Spencer Sun for preparation of the manuscript.

This work was supported in part by the Medical Research Service of the Veterans Administration and by grant AM-21923 from the National Institutes of Health.

\section{References}

1. Linker, A., and T. D. Kelland. 1963. Urinary Acid mucopolysaccharides in normal man and in Hurler's syndrome. Proc. Soc. Exp. Biol. Med. 113:743-746.

2. Manley, G., M. Swern, and J. Hawksworth. 1968. Excretion pat- 
terns of glycosaminoglycans and glycoproteins in normal human urine. J. Clin. Pathol. 21:339-345.

3. Staprans, I., S. J. Garon, J. Hopper, Jr., and J. M. Felts. 1981. Characterization of glycosaminoglycans in urine from patients with nephrotic syndrome and control subjects, and their effects on lipoprotein lipase. Biochim. Biophys. Acta. 678:414-422.

4. Badin, J., M. Schubert, and M. Vouras. 1965. Plasma polysaccharide fraction containing uronic acid in normal subjects and in patients with rheumatoid arthritis. J. Clin. Invest. 34:1317-1323.

5. Bollet, A. J., M. W. Seraydarian, and W. F. Simpson. 1957. Acid mucopolysaccharides in normal serum. J. Clin. Invest. 36:1328-1332.

6. Taniguchi, N., N. Moriya, and I. Nanba. 1974. Isolation and preliminary characterization of glycosaminoglycans in human plasma. Clin. Chim. Acta. 50:319-328.

7. Calatroni, A., P. V. Donnelly, and N. DiFerrante. 1969. The glycosaminoglycans of human plasma. J. Clin. Invest. 48:332-343.

8. Felts, J. M., I. Staprans, and R. A. Gorman. 1983. A glycosaminoglycan activator of lipoprotein lipase in human plasma. Life Sci. 32: 1659-1664.

9. Li, Y. T. 1967. Studies on the glycosidases in jack bean meal. Isolation and properties of $\alpha$-mannosidase. J. Biol. Chem. 242:54745480 .

10. Saito, H., T. Yamagata, and S. Suzuki. 1968. Enzymatic methods for the determination of small quantities of isomeric chondroitin sulfates. J. Biol. Chem. 243:1536-1542.

11. Yamada, K., Y. Fujita, and S. Shimizu. 1982. The effect of digestion with keratanase (Pseudomonas sp.) on certain histochemical reactions for glycosaminoglycans in cartilaginous and corneal tissues. Histochem. J. 14:897-910.

12. Linker, A., and P. Hovingh. 1975. Structural studies of heparitin sulfate. Biochim. Biophys. Acta. 385:324-333.

13. Horner, A. A. 1967. Electrophoresis of acid mucopolysaccharides in agarose gel. Can. J. Biochem. 45:1009-1013.

14. Dole, V. P. 1956. A relation between non-esterified fatty acids in plasma and the metabolism of glucose. J. Clin. Invest. 35:150-154.

15. Trout, D. L., E. H. Estes, and S. J. Friedberg. 1960. Titration of free fatty acids of plasma: a study of current methods and a new modification. J. Lipid Res. 1:199-202.

16. Staprans, I., J. M. Felts, and R. J. Butts. 1983. Quantitative de- termination of individual glycosaminoglycans in plasma by concanavalin A rocket electrophoresis. Anal. Biochem. 134:240-244.

17. Bitter, T., and H. M. Muir. 1962. A modified uronic acid carbazole reaction. Anal. Biochem. 4:330-334.

18. Boas, N. F. 1953. Method for the determination of hexosamines in tissues. J. Biol. Chem. 204:553-563.

19. Terho, T. T., and K. Hartiala. 1971. Method for determination of the sulfate content of glycosaminoglycans. Anal. Biochem. 41:471476.

20. Roe, J. H. 1955. The determination of sugar in blood and spinal fluid with anthrone reagent. J. Biol. Chem. 212:335-343.

21. Cifonelli, J. 1968. Reaction of heparitin sulfate and nitrous acid. Carbohydr. Res. 8:233-242.

22. Jansson, L., and V. Lindahl. 1970. Evidence for the existence of a multichain proteoglycan of heparan sulfate. Biochem. J. 117:699-702.

23. Lowry, O. H., N. J. Rosebrough, A. L. Farr, and R. V. Randall. 1951. Protein measurement with the Folin phenol reagent. J. Biol. Chem. 193:265-275.

24. Laemmli, U. K. 1970. Cleavage of structural proteins during the assembly of the head of bacteriophage T4. Nature (Lond.). 227:680-685.

25. Segrest, J. P., and R. L. Jackson. 1972. Molecular weight determination of glycoproteins by polyacrylamide gel electrophoresis in sodium dodecyl sulfate. Methods Enzymol. 28:54-63.

26. Martz, M. D., and A. F. Krivis. 1971. Thin layer chromatography of hexosamines on copper impregnated sheets. Anal. Chem. 43:790791.

27. Juvani, M., C. Friman, H. Ranta, and O. Wegelius. 1975. Isolation and characterization of undersulfated chondrotin-4-sulfate from normal human plasma. Biochim. Biophys. Acta. 411:1-10.

28. Murata, K., and Y. Horiuchi. 1977. Molecular weight-dependent distribution of acidic glycosaminoglycans in human plasma. Clin. Chim. Acta. 75:59-69.

29. Nakashima, Y., N. DiFerrante, R. L. Jackson, and H. J. Pownall. 1975. The interaction of human plasma glycosaminoglycans with plasma lipoproteins. J. Biol. Chem. 250:5386-5392.

30. Friman, C., M. Juvani, and B. Skrifvars. 1977. Acid glycosaminoglycans in plasma. Scand. J. Rheumatol. 6:177-182.

31. Brenner, B. M., C. Baylis, and W. M. Deen. 1976. Transport of molecules across renal glomerular capillaries. Physiol. Rev. 56:502-534. 